\title{
Lugar y no-lugar en América Latina. Una propuesta para hacer emerger la ciudad ontológica versus la ciudad óntica revalorizando la identidad
}

\author{
Place and Non-Place in Latin America. \\ A proposal for the emergence of the ontological city against the ontical city, \\ revitalizing identity
}

\section{<Resumen>}

El aumento desenfrenado de no-lugares invade nuestras ciudades y nuestras culturas, ante lo que se propone hacer emerger la fuerza de la identidad de América Latina para que su resonancia se concretice en su arquitectura a fin de anudarla al territorio y a la memoria de sus ciudadanos como posibilidad de ofrecer un lugar.

$<$ Abstract $>$

In order to face the uncontrolled increase of non-places in our cities and in our cultures, the strong identity of Latin America should arise to reflect itself in its architecture, which would get rooted in the territory and in the memory of its citizens as means to offer a place.

PALABRAS CLAVE>

LUGAR / NO-LUGAR / ARQUITECTURA / IDENTIDAD

$<K E Y W O R D S>$

PLACE / NON-PLACE / ARCHITECTURE / IDENTITY

"La ciudad parece estar consumiéndose poco a poco, pero sin descanso, a pesar de que sigue aqui. No hay forma de explicarlo; yo sólo puedo contarlo, pero no puedo fingir que lo entiendo».

Paul Auster ${ }^{1}$

\section{Introducción}

Últimamente los no-lugares pululan incesantes en el aire, en boca de todos, pareciera que se habla más de los no-lugares que de los lugares. Desde artículos de revistas de fin de semana, hasta en exposiciones, películas, etc., los no-lugares se han convertido en un término de moda, sugerente para nuestros días.

\section{No-l ugares}

Desde la publicación del libro de Marc Augé los no-lugares han tomado una presencia que es interesante de analizar. El autor, por oposición al lugar, los identifica como un «espacio que no puede definirse ni como espacio de identidad, ni como relacional, ni como histórico»². Augé los presenta como

\footnotetext{
Laura Gallardo Frías es arquitecta por la Universidad Politécnica de Cataluña. Doctora ( ) en Arquitectura y Urbanismo por la Universidad Politécnica de Madrid-Universidad de Chile.

Ha participado en trabajos de investigación en la escuela de arquitectura de Toulouse y en la de Barcelona. Ha colaborado como profesora adjunta en la Universidad de Chile y la Diego Portales y ha trabajado en distintos estudios de arquitectura de Barcelona, Toulouse y Santiago.

Auster, Paul. In the Country of the last things. Guillermo Schavelzon \& Asoc, Agencia Literaria, 1987. Trad. Cast: Ma Eugenia Ciocchini. El país de las últimas cosas. Anagrama, Barcelona, 1994, pág 33.

2 Augé, Marc. Non Lieux. Introduction à une anthropologie de la surmodernité. Ed. du Seuil,1992. Trad. cast: Margarita Mizraji. Los no lugares. Espacios del anonimato. Una antropología de la sobremodernidad. Barcelona Ed. Gedisa S.A. 2004, pág. 83
} 
característicos de la sobremodernidad. Pero al igual que la racionalidad se sirve de la irracionalidad para constituirse como tal, también los lugares se sirven de los no-lugares para constituirse como tales. Si revisamos antecedentes, podemos comprobar que los nolugares han existido desde que hay lugares.

Otro de los ejemplos más contundentes a cerca de los no-lugares lo tenemos con Thomas More (Tomás Moro), quien ya en 1516, nos hablaba de «utopía»${ }^{3}$, palabra inventada por él mismo compuesta por los términos griegos $u=$ no y topos = lugar, o sea, no-lugar, es decir, en ninguna parte o «en algún lugar no existente». El éxito de esta obra sirvió para que la palabra perdurara en el tiempo.

En el no-lugar de Moro su isla, que se perfila como un sueño irrealizable, existen casas y calles muy cuidadas con una urbanización perfecta, no hay lujosos edificios pero tampoco pobres, no existe la propiedad privada, no hay diferencia de clases ${ }^{4}$, siendo su sistema político una perfecta democracia donde se trabaja seis horas al día y el resto se dedica a cultivar el espíritu y a las actividades de tipo lúdico; un no-lugar donde el oro no tiene ningún valor, siendo su principal problema saber en qué consiste la felicidad del hombre y si reside en una o varias cosas.

Moro se refería a un no-lugar como un lugar lejano e inaccesible, a diferencia de Augé que plantea la llegada a los no-lugares y aún más: que se han materializado invadiendo nuestras ciudades. Para Augé los no-lugares son tanto «las instalaciones necesarias para la circulación acelerada de personas y bienes (vías rápidas, empalmes de rutas, aeropuertos) como los medios de transporte mismos o los grandes centros comerciales, o también los campos de tránsito prolongado donde se estacionan los refugiados del planeta ${ }^{5}$.

Por tanto, se podría plantear que mientras los lugares en la arquitectura están referidos a las personas, teniendo un carácter «remisional», es decir, remitidos o plegados hacia el ser humano, donde éste se siente integrado, como parte-de; la ausencia de remisión hacia el ser, este sentimiento de estar fuera-de se le puede atribuir al no-lugar.

Ausencia que también se hace latente cuando se comienzan a repetir las mismas edificaciones por todas partes, queriendo «representar a otros sitios que no se parecen en nada» como indica Smithson (1968) en su texto A PROVISIONAL THEORY OF NON-SITES que para llegar al concepto de non-site, parte explicando que el plano de una calle, de una casa o un plano topográfico, que denomina «imágenes bidimensionales lógicas», se diferencian de las «imágenes naturales o realistas» en que raras veces tienen parecido con aquello que representan, por lo que serían «metáforas bidimensionales». Ahora bien, Ilevando esta idea a las tres dimensiones, llega al concepto de «Non-site» (an indoor earthwork) mediante esta metáfora dimensional donde un sitio puede representar a otro sitio que no tenga nada que ver.

Así, los no-lugares también son una consecuencia de la clonación arquitectónica, una pérdida de autenticidad, que se vuelve inalcanzable con las múltiples copias. Con lo que si la autenticidad ligada a la identidad se caracteriza por anudar la arquitectura al territorio, por construir los lugares enlazando pasado y presente; al fundirse con el movimiento y la velocidad disipan la posibilidad de otorgar un significado, ya que con este copiarse sin cesar se promueve la eliminación de cualquier tradición pues ésta implica la transmisión del pasado. Así, más que ir forjando una ciudad con la sabiduría del pasado y del presente, se van acumulando objetos inconexos.

Con ello se pone de manifiesto la clonación y la formación de no-lugares asociados a ella, se quiebra el aquí y el ahora: el «aura» ${ }^{6}$, lo que implica una pérdida de esencia en la arquitectura al ser copiada una y otra vez sin tener relación con el lugar, las gentes, el clima, etc., de donde se inserta, con lo que se diluye la identidad que implica una pérdida en la posibilidad de dar lugar, pues en vez de producirse una apertura, se produce una

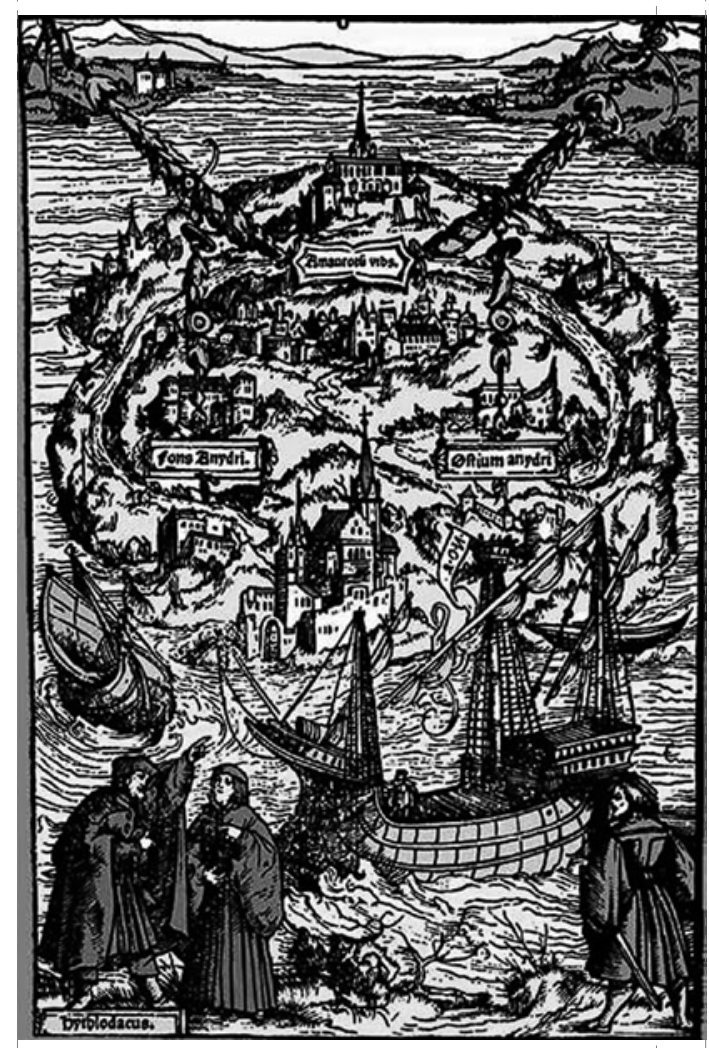

«La Isla Utopía», ilustración de Ambrosi Holbein, Biblioteca Agustana para la edición de 1518. Fuente: WWw. geographos. com/BLOGRAPHOS/?p=113

especie de cerramiento, de imposibilidad de dar lugar, llegando a la raíz de la definición de no-lugares o lugares que nos son ajenos.

Esta pérdida de «alma», relacionada con la "pérdida de sentido», está íntimamente ligada a los no-lugares o «lugares sin alma», "lugares sin sentido» y en definitiva a los lugares fuera de lugar. Pérdida de sentido que saca a las cosas de quicio y así, al edificar, en vez de materializar singularidades se erigen sinlugaridades con lo que el ser humano queda des-lugarizado y ya no se puede hablar de arquitectura.

Se podría especular sobre el concepto de nolugar en América Latina definiéndolo a grandes rasgos como la fragmentación resultante entre distintas piezas y tejidos que no tienen nada que ver entre ellos, pero que dispuestos unos al lado de otros, producen un fuerte contraste que se hace más evidente sin los maquillajes de semejanza a lo antiguo o contiguo que se suele dar en Europa. No-lugares que provocan además de una explosión en el entorno

\footnotetext{
Moro, Tomás. Utopía. Se recuerda que este libro fue publicado en castellano en el año 1637 con un prólogo de Francisco de Quevedo.

Aunque como es sabido, las mujeres en este «estado ideal» estaban sometidas a los hombres.

Augé, Marc. Non Lieux. Introduction à une anthropologie de la surmodernité. Ed. du Seuil,1992. Trad. cast: Margarita Mizraji. Los no lugares. Espacios del anonimato. Una antropología de la sobremodernidad. Barcelona Ed. Gedisa S.A. 2004, pág. 41

Se hacer referencia al concepto de «aura» de Walter Benjamin, a la que define como «la manifestación irrepetible de una lejanía (por cercana que puede estar)» (Benjamin. Walter. La obra de arte en la era de su reproducibilidad técnica, 1936, pág. 5. Escuela de Filosofía Universidad Arcis, versión digital: www.philosophia.cl), el autor pone como ejemplo el descansar viendo una cordillera y siguiendo con la mirada como una hoja se mece en su rama, «sería aspirar el aura de esas montañas, de esa rama».
} 


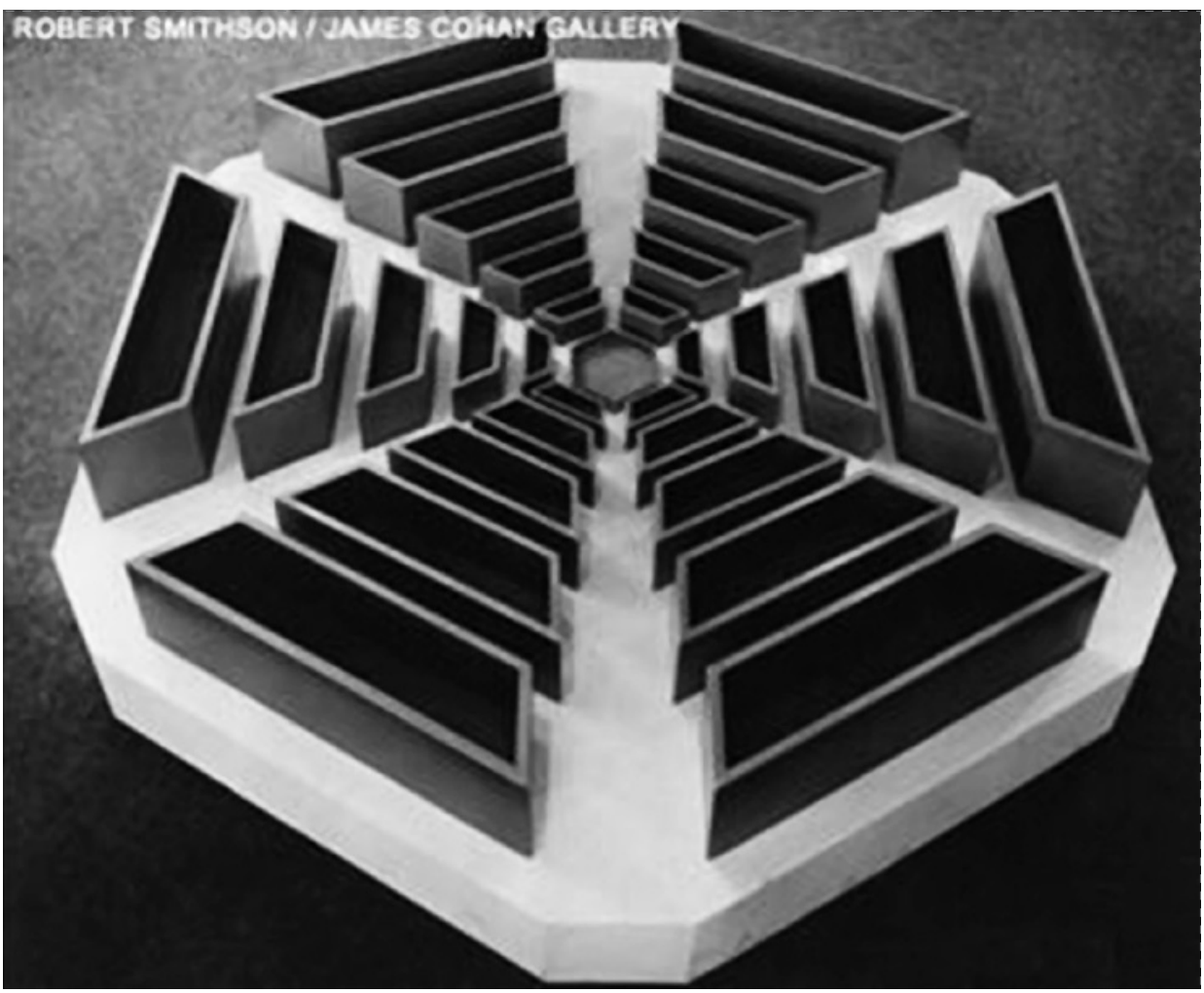

Escultura A NONSITE1, Pine Barrens, New Jersey. Iwinter 1968; blue aluminum with sand, aerial photograph/map. 12»h x 16 1/2»x 65 1/2». Collection of Virginia Dwan. Fuente de la imagen: http://www.robertsmithson.com/sculpture/nonsite $350 . h t m$ ser antropocéntricas, es decir, han dejado de ser pensadas para el Dasein, para el ser del ente, pasando a estructurarse en función de los entes: sobre todo los flujos, entendiendo como tales las carreteras, autopistas, etc., ligados a la economía. Pudiendo considerar el surgimiento de una ciudad «existintiva», más que de una ciudad "existencial» ${ }^{8}$, es decir, más relacionada con lo óntico que con lo ontológico.

Por lo que se deja abierto un diálogo invitando a la reflexión sobre la ciudad ontólogica, ya que en «toda ontología, por rico y sólidamente articulado que sea el sistema de categorías de que dispone, es en el fondo ciega y contraria a su finalidad más propia si no ha aclarado primero suficientemente el sentido del ser y no ha comprendido esta aclaración como su tarea fundamental» ${ }^{9}$

\section{Lugar y arquitectura}

Con lo que el reto consiste en, teniendo en cuenta los requerimientos actuales de la movilidad y el cambio, asociados a la velocidad, detenernos para avanzar, pararnos para pensar, en primer lugar acerca de las necesidades del ser humano y en concreto en América Latina ligadas a su identidad para poder llevarla al ámbito de la arquitectura y desde este ahí, ofrecer una apertura, una posibilidad de formar lugares donde el ser humano se sienta representado e integrado.

A pesar de la característica efímera del tiempo, cuando éste consigue instalarse, permanecer, habitar un espacio presente, daría o formaría lugar. Así, se puede definir el lugar como algo, a pesar del movimiento, que es capaz de instalarse en el momento, lugar relacionado con la quietud en el seno del movimiento, con el reposo dentro de lo pasajero. Lugar como capacidad o posibilidad de habitar el presente.

Morales subraya que la detención en un determinado lugar lo convierte en un «paraje». No obstante, «el detenerse como el 'parar' llevan consigo las nociones de 'preparar', 'disponer', y 'proporcionar' inherentes al término latino parare, significativas de que dicha detención no supone pasividad, sino que nos conduce a otras formas de acción» ${ }^{10}$.

\section{Óntico-Ontológico}

Con lo que se podría afirmar que se está pasando de una ciudad ontológica a una ciudad óntica. A partir de la definición de ente y ser que enuncia Heidegger en su obra SER Y TIEMPO, donde «ente es todo aquello de

Ha contribuido a este paso un «cambio de escala» (Augé), donde el mundo es cada vez más una ciudad y la ciudad cada vez más un mundo. Donde las ciudades han dejado de
Heidegger, Martin. Sein und Zeit. Tubinga, 1927. Trad. Cast. Jorge Eduardo Rivera C. Ser y Tiempo. Editorial Universitaria, Santiago de Chile, 2005, pág. 30.

8 Rivera, Jorge Eduardo. En Notas del traductor de Ser y tiempo, 2005:456.

9 Heidegger, Martin. op. cit., pág. 34

Morales, José Ricardo. Arquitectónica. Sobre la idea y el sentido de la arquitectura. Editorial Biblioteca Nueva, Madrid, 1999, p 161 
Con lo que se pone de manifiesto que el lugar, además de tener como esencia el reposo, también lleva asociado el movimiento que implica la continua búsqueda de lugar. «Tener lugar quiere decir poder estar fuera de lugar, tener que moverse y por tanto devenir sentido » ${ }^{11}$, pues si se encontrara sería el reposo absoluto, la muerte. Por lo que se propone una reflexión a cerca de la arquitectura como capaz de generar, de aspirar a la formación de lugares que en sí llevan asociados tanto el reposo como el movimiento, su búsqueda. Arquitectura como cobijo de reposo en movimiento, pero iniciando esta reflexión desde el ser humano y su identidad.

Así, se plantea como una necesidad el trabajar en equipos multidisciplinares para analizar destilar y concretizar la identidad, tanto de cada país en particular, como la que los unifica conformando Latinoamérica, a fin de que funcione como un «resorte para la acción más que como una forma de contemplación» ${ }^{12}$

Si bien hay muchas maneras diferentes de definir la identidad, se puede considerar, según indican Vergara y Vergara ${ }^{13}$, como «una trama de niveles, no siempre concordantes», con lo que es relevante además de mirar hacia afuera, el mirar hacia adentro en todos los niveles.

No se propone una genealogía de la identidad, sino una continua búsqueda. Curiosamente la palabra identidad significa, según la RAE, tanto la cualidad de lo idéntico, como las cualidades que caracterizan, ya sea un individuo o una colectividad, de los demás, es decir, las diferencias. Así, la identidad es en sí un fracaso como indica Lévinas ${ }^{14}$, pues implica una búsqueda que lleva a volver a encontrarse pero al volver al yo ya es otro. Por lo tanto, es importante no sólo buscar las uniones sino las rupturas, no sólo un hilo conductor sino sus fragmentos y las líneas y puntos de fuga, las riquezas de las mezclas y la diversidad. Una continua búsqueda que en sí encierra la esencia de la identidad.
Con lo que se plantea una arquitectura, que más que imponerse des-lugarizada a la que haya que incorporarse, que parta desde la identidad Latinoamericana para que ofrezca un lugar, pero comenzando por pensar en sus habitantes, un «lugar desde el habitar» (Heidegger) desde el ser latinoamericano. Arquitectura como búsqueda continua de las necesidades del ser y su relación del interior con el exterior, del cuerpo y alma; éste sería un punto interesante de partida para las reflexiones de los arquitectos cuya máxima función a través de la arquitectura es el dar lugar.

Pues como indica Aristóteles el lugar es «lo que ejerce cierta influencia al cuerpo que está en él» ${ }^{15}$, pero también es vital que el cuerpo que está en él tenga la posibilidad de ejercer cierta influencia sobre el lugar. Equilibro entre lo que envuelve y lo envuelto, afinidad donde lo relevante reside en la coincidencia permanente entre las dos fronteras, en la «constante de vecindad».

Más que pasar del no-lugar al lugar, pues ambos han coexistido desde siempre, se propone hacer emerger el lugar por sobre el no-lugar.

Y así, desde la arquitectura destinar nuestra finalidad del proyecto a «imaginar el 'lugar', construir el 'espacio' y hacer posible y elocuente la 'belleza' en el discurrir de la vida» ${ }^{16}$.

Para lo que se propone revalorizar la identidad de América Latina unida a su genius loci para que sus resonancias impregnen una arquitectura que surja para cobijar el reposo del movimiento, para darle quietud a un continuo cambio, tanto del ser humano como de su identidad. Arquitectura como un receptáculo capaz de dar lugar, de albergar, receptiva a los cambios pero conservando su identidad, su esencia que permanece más allá de las transformaciones. Arquitectura como envolvencia de lo «in-volvente», como cobijo del constante devenir.

\section{Referencias bibliográficas}

Libros y revistas:

Augé, M. «Non Lieux. Introduction à une anthropologie de la surmodernité. Ed. du Seuil,1992. Trad. cast: Margarita Mizraji. Los no lugares. Espacios del anonimato. Una antropología de la sobremodernidad». Barcelona, Ed. Gedisa S.A., 2004.

Auster, P. «In the Country of the last things». Guillermo Schavelzon \& Asoc, Agencia Literaria, 1987. Trad. Cast: M ${ }^{a}$ Eugenia Ciocchini. El país de las últimas cosas. Anagrama, Barcelona, 1994.

Benjamín, W. «La obra de arte en la era de su reproducibilidad técnica», 1936. Escuela de Filosofía Universidad Arcis, versión digital: www. philosophia.cl

Fernández Alba, A. «Sobre la naturaleza del espacio que construye la arquitectura (Geometría del recuerdo y proyecto del lugar)». Real Academia de Bellas Artes de San Fernando, Madrid, 1989.

Ferrater Mora, J. «Diccionario de filosofía abreviado». Editorial Sudamericana, Buenos Aires, 2000.

Hernández Martínez, A. «La clonación arquitectónica». Editorial Siruela, Madrid, 2007.

Heidegger, M. «Construir, habitar, pensar». Alción Editora, Argentina, 1997.

Heidegger, M. «Sein und Zeit». Tubinga, 1927. Trad. Cast. Jorge Eduardo Rivera C. «Ser y Tiempo». Editorial Universitaria, Santiago de Chile 2005.

Lévinas, E. «Humanisme de l'autre homme». Falta morgana. Monpellier, 1972. Traducción castellana: Daniel Enrique Guillot. «Humanismo del otro hombre». Siglo xxı editores, México, 2006.

Morales, J.R. «Arquitectónica. Sobre la idea y el sentido de la arquitectura». Editorial Biblioteca Nueva, Madrid, 1999.

Moro, Tomás. Utopía.»De optimo statu rei publicae deque nova insula Utopia». Traducción:

Francesc L. Cardona. Utopía. Edicomunicación, Barcelona, 1994

Pardo, J.L. "Las formas de la exterioridad». Ed. Pretextos, Valencia, 1992

Vergara Estévez, J; Vergara del Solar J. «Cuatro tesis sobre la identidad cultural latinoamericana. Una reflexión sociológica». Revista de Ciencias Sociales, número 012. Universidad Arturo Prat. Iquique, Chile, 2002

Páginas webs:

www.robertsmithson.com

www.rae.es/rae.html

www.philosophia.c

1 Pardo, José Luis. Las formas de la exterioridad. Ed. Pre-textos, Valencia, 1992, pág. 119

12 Biafini, Patricia. Lo propio y lo ajeno en interrelación palpitante, En: Nueva Sociedad No 99, enero-febrero, Caracas, 1989 p 98 . Citado Vergara Estévez Jorge. Vergara del Solar Jorge Cuatro tesis sobre la identidad cultural latinoamericana. Una reflexión sociológica. Revista de Ciencias Sociales, número 012. Universidad Arturo Prat. Iquique, Chile, 2002, p 80

13 Vergara Estévez, Jorge. Vergara Del Solar Jorge. op. cit., pág. 79

14 Lévinas, Emmanuel. Humanisme de l'autre homme. Falta morgana. Monpellier, 1972. Traducción castellana: Daniel Enrique Guillot. Humanismo del otro hombre. Siglo xxı editores, México, 2006. Pág. 116.

15 Aristóteles libro IV de la Física. Citado en Ferrater Mora, José. Diccionario de filosofía abreviado. Editoria Sudamericana, Buenos Aires, 2000, pág.226.

16 Fernández Alba, Antonio. Sobre la naturaleza del espacio que construye la arquitectura (Geometría del recuerdo y proyecto del lugar). Real Academia de Bellas Artes de San Fernando, Madrid, 1989, pág. 9. 